\title{
Statistical Analyses of Productivity Model Parameters for Process Improvement
}

\author{
Zahid Hussain ${ }^{1}$ \\ 1 Sarhad University of Science and Information Technology, Peshawar 25000, Pakistan \\ e-mail: zahid.btech@suit.edu.pk
}

\begin{abstract}
Productivity modeling and validation is the assessment of data to establish scientific indications that a process is stable. The aim of this paper is to present a novel approach using statistical analyses for process improvement. This study highlights the process behavior of three different lathe machines unit with the intention to replace one of them. The research methodology has illustrated by producing a steel rod of 3.175 millimeter diameter based on 180 samples collected from each machine. For statistical data value analysis, MS Excel 2016 and Minitab 18 were utilized. The results showed that lathe machine 1 and 2 had an equivalent inconsistency, but significantly different data spreads. Similarly, the throughput for machine 2 was higher with greater variability as compared to machine 1 while machine 3 encountered a low rate of throughput. On the basis of the fallouts of the analysis, the research team has officially suggested to substitute lathe machine 3 .
\end{abstract}

Keywords: statistical analyses, process modeling, experimental design, process improvement.

\section{INTRODUCTION}

The productivity modeling is a commotion used to ascertain the important contributions and yields of a certain manufacturing process. It guesstimates the steady state performance at optimum working settings and shape process model parameter crosswise the operational range [1]. This commotion involves three process stages. The Screening Stage: in which all conceivable noteworthy inputs and outputs of the process are identified and further conducting a sequence of running certain experiments so as to minimize any tilt to these process inputs and outputs [2]. These experiments help to develop preliminary process model for studying the relationships between the process variables. The Mapping Stage: here the performance of the key factors over their predictable working ranges is mapped through a sequence of more exhaustive experiments [3]. The Passive Step: during this stage the process is allowed to run at minimal working conditions for estimating the process reliability and fitness[4]. Process enhancement is an important fragment of any unremitting development program for the persistence to examining the physical fitness of the running process [5]. Apparently all the manufacturing and measurement practices display process variation. Though the process variability is an amassing of various sources of variation that have arisen through the production process, the critical actions of process are to recognize and enumerate these foundations of variation so that they may be diminished and improve the process [6]. There are two such types of process variations. Controlled variation: Variation which is considered stable and present a reliable design of variation over time, however such type of variation is normally random which will present a uniform variation about a continuous level [7]. Uncontrolled variation: a variation that fluctuates over time that is why it is unpredictable, however such type of variation normally contains some edifice [8].

\section{Outlines of the process model}

The first step is to develop the model with desired parameters under study for validation 


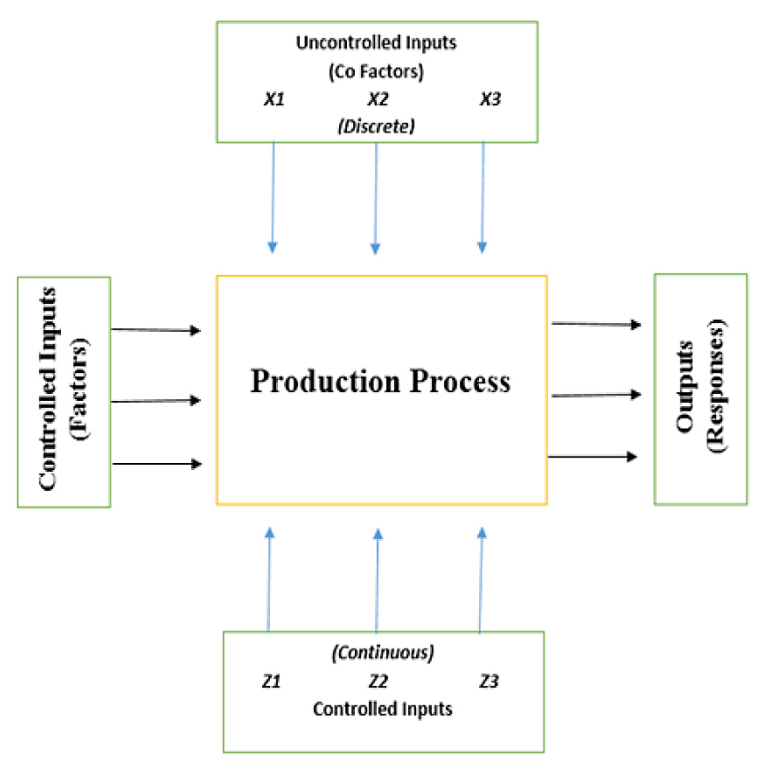

Fig. 1. Process black box

[9]. In this perspective a black box model as shown in Figure 1 is motivated by necessary input variables which may either be controlled or uncontrolled and presented as process factors and responses correspondingly. The inputs perform some process changes and produce the required outputs. These outputs usually present some specific of the process and usually measurable [10]. Further, they could be sampled in order to perceive and apprehend how they actually perform and relay to each other. The process factors and responses are pigeonholed rendering to variable type that demonstrates the expense of evidence they cover [11].

\section{Experimental design considerations}

For the process reliability and capability, it is normally intended to distinguish between the interactions among the factors and responses. During conducting the current study, two types of responses relationships are addressed [12].

Correlation: when an experimental change of a single process variable is supplemented by a change of another one. Causality: when there exists a causal relationship between the two process variables in case a variation in the range of one process variable brings a variation in the other one respectively[13].Usually, during experimental investigation, it is intended to determine correlation and confirm causal interactions using various techniques in order to manipulate experimental data [14].

\section{Productivity parameters considerations}

The principal action of the productivity parameters considerations for building modeling and validation is to gather the required data in order to present conclusions for the maximum and effective improvement [15]. The steps involve are presented in Figure 2. The furthermost significant step considerably is the planning that should engender like a declaration of the goals, expressive process validation model, explanation of the sampling, depiction of the data collection technique, jobs with errands, configuring, and putting away a sketch of the process data analysis [16]. All those verdicts that distress the significance of the process characterization will likely be directed throughout the planning stage. The process parameters should be directed according to the plan supported with all omissions renowned [17]. Data collection is fundamentally the implementation of the sampling strategy. It is based on the fact that if a good task were completed during the planning phase, then the current step becomes much more straightforward. It is significant to complete the plan as strictly as conceivable and to highlight any exemptions [18]. Data analysis and explanation is the mishmash of quantifiable statistical analysis practices similar to ANOVA, regression and correlation followed by graphical techniques that exhibit scatter plot, histograms and box plots which are practical to the data collection for the accomplishment of the process parameters [19]. Reporting is also a critical step which should not be disregarded. In order to create a revealing report, it must be ensured that others concerned

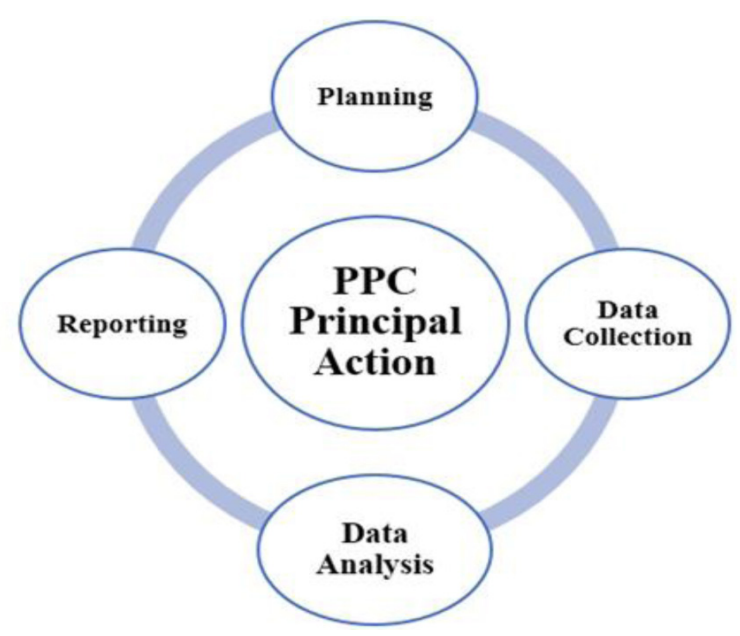

Fig. 2. Productivity parameters sequences 
have the chance to open access to the material made by the production [20]. The main impartial of this paper is to plan and develop productivity modeling for a real industrial process validation with the help of engineering statistical methods. Practical work has been conducted in a company's mechanical workshop where three lathe machines are engaged to produce the desired product. This research work will also extend a group of engineering statistical approaches to put on the experimental models into actual industrial conditions scientifically that involve the study and development of the process improvement rate [21].

\section{MODEL ASSUMPTIONS}

Primarily, it is assumed that the process may sufficiently be modeled as the total of a methodical and random constituent. The methodical constituent is the mathematical model portion while the random constituent is the noise or errors existing in the process system [22]. It may also be assumed that the methodical constituent is stable over the level of working environments while the random constituent has a continuous position, distribution and spread arrangement [23]. Lastly, the data collection measuring strategy has been deliberated and confirmed to the anticipated exactness and correctness.

\section{Continuous linear production model}

The continuous linear production model is based on numerical function that transmits descriptive process variables to a solitary continuous response process variable that is:

$$
y=a_{0}+\sum_{i=1}^{p} a_{i} f\left(x_{i}\right)+e
$$

The expression explains that if there exist any $\mathrm{p}$ explanatory process variables, then the required response is demonstrated through a constant time and over a total of functions of the process explanatory variables with some expected error [24].

\section{One-way ANOVA}

A one-way outline involves a single process factor with numerous levels and manifold annotations at each considerable level while the outline computes the mean of the annotations inside each level factor. However, the residuals will explain the dissimilarity within each process level [25]. By doing so the nonconformity of the mean of individual level of the grand mean is analyzed to recognize roughly about the unusual effects. Similarly, the variation is compared within different levels to the dissimilarity across levels using the expression 2 that specifies that any jth value, from a specific level $i$, is the total of basically three constituents that is the grand mean followed by the deviation of separately level mean from the grand mean and the residual [26].

$$
y_{i j}=m+a_{i}+e_{i j}
$$

Approximation for the one-way arrangement may be performed by calculating the total variance, within level followed by the across level variance and could be summarized using ANOVA table as shown in Table 1 to recognize any significance pertains to factor levels.

Here:

$$
y_{i}=\frac{1}{j} \sum_{j=1}^{j} y_{i j}
$$

And

$$
\mathrm{y}=\frac{1}{N J} \sum_{i=1}^{N} \sum_{j=1}^{j} y_{i j}
$$

Using expression 3 and 4 with ANOVA, testing is conducted to find that the observed process data for any significant variance between their means [27]. If it is further assumed that the data observations within each factor level hold the same variance, then the variance of each factor level is calculated and mere these observations together to study the estimate of the overall process data variance [28]. It can be exposed that the specified assumptions regarding the process data, the ratio between the level of the mean square

Table 1. ANOVA table for analysis

\begin{tabular}{|c|c|c|c|c|}
\hline Source & SS (sum of squares) & DF & MS (mean square) & $F_{0}$ \\
\hline Factor & $S S_{F}=J \sum(y i-y)$ & $\mathrm{N}-1$ & $M S_{F}=S S_{F} /(N-1)$ & $M S_{F} / M S_{E}$ \\
\hline Residual & $S S_{E}=\sum y \sum(y i-y)$ & $\mathrm{N}(\mathrm{J}-1)$ & $M S_{E}=S S_{E} /(N(J-1))$ & \\
\hline Error. Total & $S S_{T}=\sum y \sum(y i-y)$ & $\mathrm{NJ}-1$ & & \\
\hline
\end{tabular}




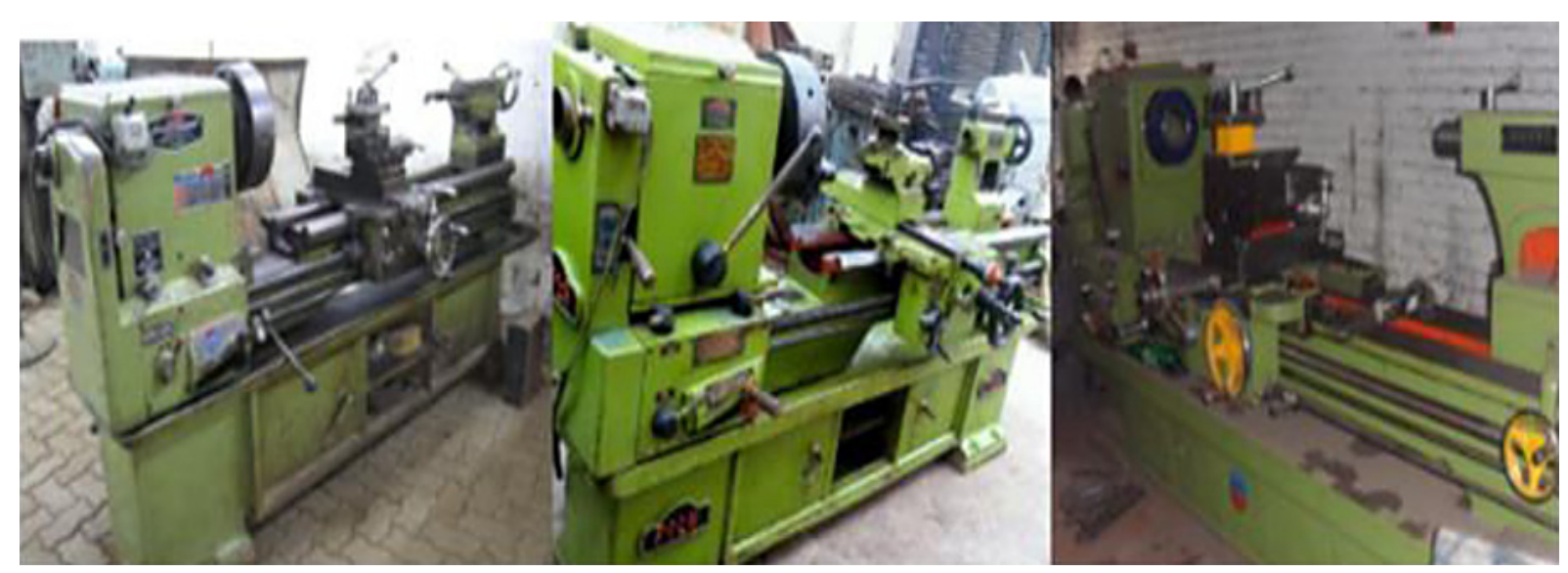

Fig. 3. Lathe machines in Frontier Ceramic Factory

and the mean square of residuals follows the $\mathrm{F}$ distribution with specified degree of freedom as presented in one-way ANOVA table. However, if the value of $\mathrm{F}_{0}$ is significant at any significance level, then it will clearly show that there is definitely a level upshot existing in the data [29]. Assumption: For the purpose of estimation, it is assumed that the process data can be successfully modeled as the total of a deterministic element and a random constituent. It is further assumed that the stable constituent may be modeled as the total of the overall data mean with extra influence from the level of factors [30]. It is finally assumed that the random elements are desired to be modeled with the Gaussian distribution approach with a stable data spread and location [31].

\section{METHODOLOGY AND DATA COLLECTION}

Current study emphasizes the prominence and relevance of engineering statistical approach to analyze three different lathe machines installed in Frontier ceramic industry in Peshawar city with the commitment to replace one of them. This work basically focuses on data collection, investigation and implication using statistical analysis approaches. For data values comparison, the state of the art statistical software package Minitab 18 is utilized so that evocative glitches could be highlighted. These machines are installed in mechanical workshop and are in the state of normal working conditions as shown in Figure 3.

At present the industrial unit has sufficient potential to substitute one of the machines. In this regards the research and development department of the unit had been assigned to carry out a practical a study and make an endorsement as to which specific lathe machine could be substituted. It was also decided to observe one of the utmost regularly parts produced, a steel rod of 3.175 millimeter on each of the machines and to observe which particular lathe machine is the slightest stable. The data collection process starts with performing statistical analyses containing ascertaining and working with various probability distributions followed by vigilant planning strategy. Planning is the most important step that comprises of the description of strong and brief goals, developing process sensitivity model and formulating a sampling plan.

\section{Outlining the goals}

The primary goal of this research study is to explore which specific machine is basically least constant to produce the required steel rod of desired size with a tolerance of \pm 0.003 millimeter respectively. For measurement of the process stability, a continuous variance around a mean will be considered and in case when all of the three lathe machines are observed to be stable, then the judgement will likely be based on the process inconsistency and throughput. Finally, the machine with the maximum variability and lowest productivity output will be designated for possible replacement.

\section{Sensitivity modeling}

The purpose of sensitivity modeling is to model the relationships of the identified process factors and responses by selecting a parameter and ascertain the other parameters which might have 


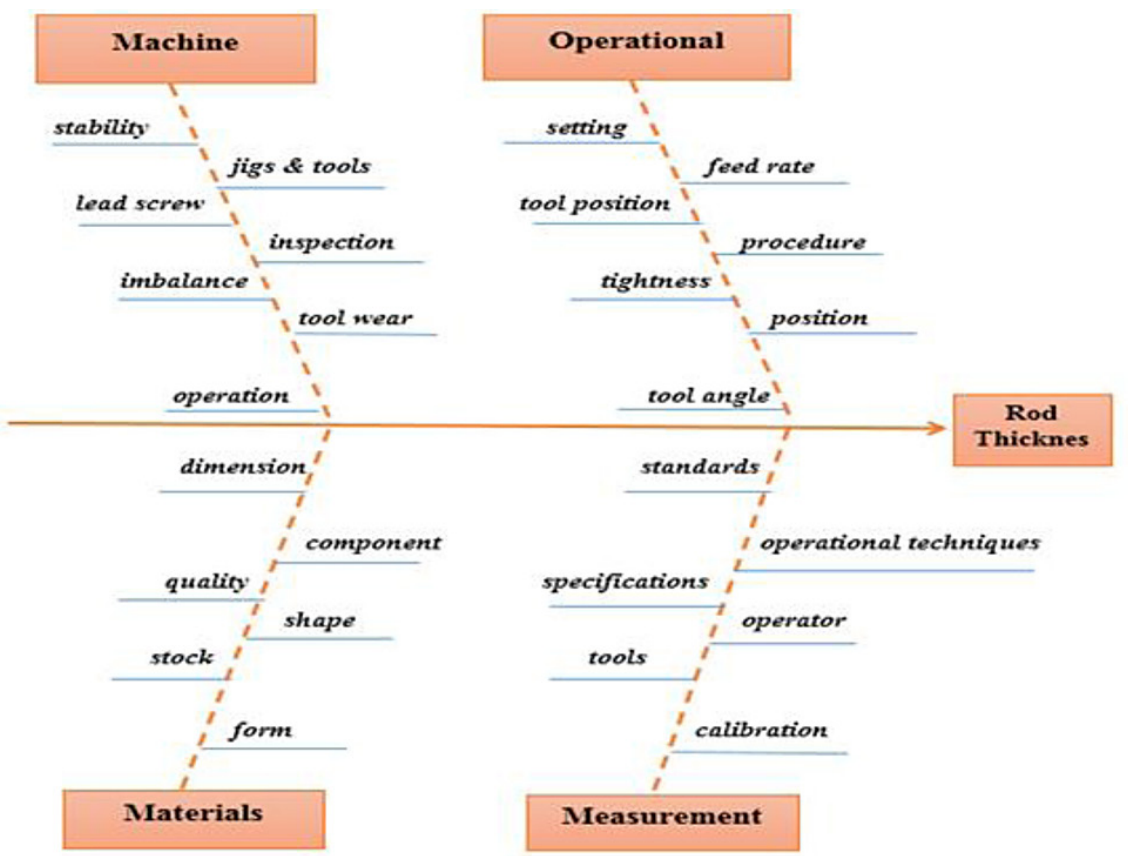

Fig. 4. Fishbone diagram for potential parameters identifications

an effect on it. This task is simply documented with a Fishbone diagram as shown in Figure 4. All the three machines will collect bar stock from the similar spot. There is a slight difference in machine, hence the concerned operator should make alterations to the rotation of the part, feed rate at which the screw is made with desired cut and stop to each machine. It is also noticeable that the same machine operator will run all machines at the same time. Measurement is also important, hence an experience inspecting engineer is assigned to collect the produced samples and record the necessary measurements. Finally, the consideration of the lathe machine physical condition which is the real aim of the current research work. The reliability of the machining process will mostly be determined by the wear on the guideways and the lead.

\section{Sampling plan}

After confirming the productivity modeling and goal declaration, the next step is to delineate the sampling plan. Here the principal objective is to define if the given process is unstable and to associate the discrepancies of the process with machines. It is also desirable to observe each machine's throughput in order to portray and compare the required productivity of these machines. For this purpose, a three day run time of the actual sampling was scheduled to study and examine the consequences based on statistical analyses. To do this a suitable time of the day is considered that did not affect the normal industrial activities. It is occasionally the situation when the lathe machines are almost idle, especially at the start of the morning shift at 9.00 and at the end of the shift at 17.00 respectively. Hence the decision is to produce samples at these available times. In order to avoid any other industrial activity conflict too ruthlessly, it was therefore acknowledged to sample only 10 pieces, two times a day, for three consecutive days from each individual machine while the daily based throughput of all three machines will be exercised accordingly. The samples produced

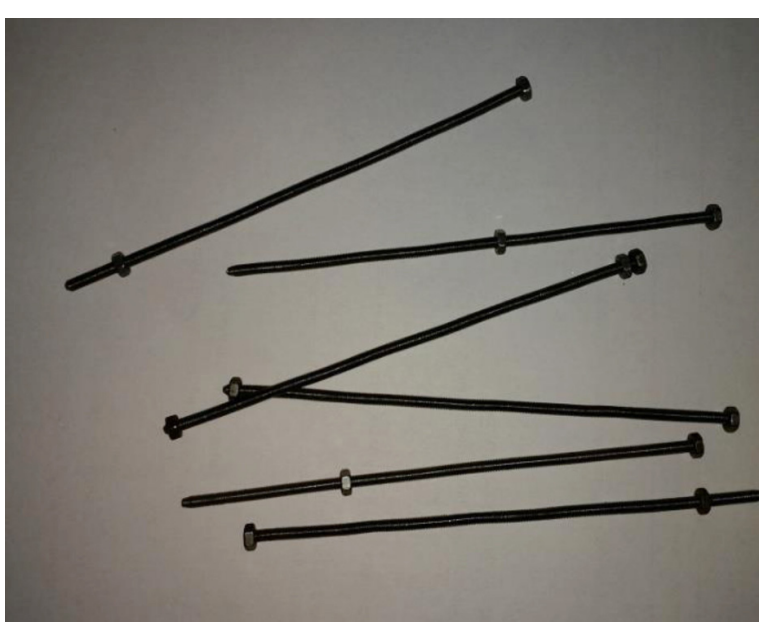

Fig. 5. Screw samples produced 


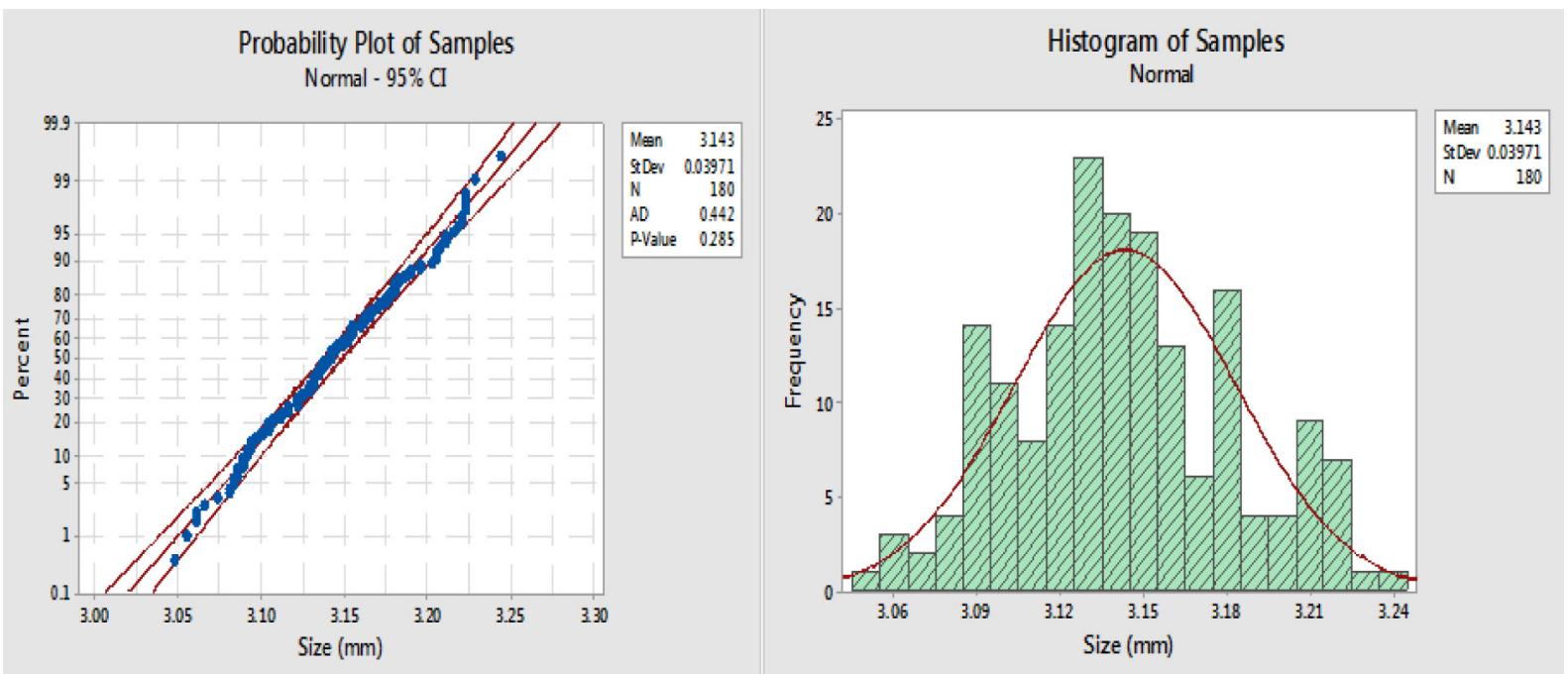

Fig. 6. Probability and histogram estimates of the data samples and process stability

and collected are shown in Figure 5 respectively. Finally, the corresponding throughput of the parts encountered from each machine would be calculated at the end of each consecutive day.

\section{DATA ANALYSIS AND RESEARCH FINDINGS}

As soon as the relevant machines data have been collected from the maintenance engineering department of the industrial unit, the required data analysis process variables were tabulated in a stake format as shown in Table 2. The next stride is to accomplish a quality status and check the data set in order to confirm normality. Figure 6 represents a fitted line of the normal distribution that signifying that sample data contributes an excellent and precise theoretical distribution, whereas the solid curve of the data histogram to the frequencies bars demonstrate that the distribution of the data is almost normal while the process stability estimations are seems to be consistent for the current production process. During the next phase, it is intended to explore which certain factors have an influence on which specific process response variability and to measure its significant influence. In this regards, it is appropriate to compare the outcomes by plotting box plots of the measured data of each machine with respect to the size of the specimen in the millimeter that is the explanatory process variance. Such comparison is shown in Figure 7 representing the box plot of the size $(\mathrm{mm})$ with respect to lathe machines. It has been revealed from the observations of the box plots that the location of data median looks to be significantly different for the three lathe machines in which the second machine showing the lowest average size of 3.1216 millimeter. On the other hand, machine 1 has the output of the highest average size of 3.1645 millimeter respectively. It is also noticeable that both machines 1 and 2 have somewhat an equivalent inconsistency, however lathe machine 3 has a considerable greater variability.

Figure 8 presents the box plot of the specimen size with respect to the Run and it may also be observed from the box plots analyses that neither the data location nor the data spread look to differ significantly. On the basis of Figure 8 findings, the box plots presentation shows that the trial time with respect to the specimen size clearly shows

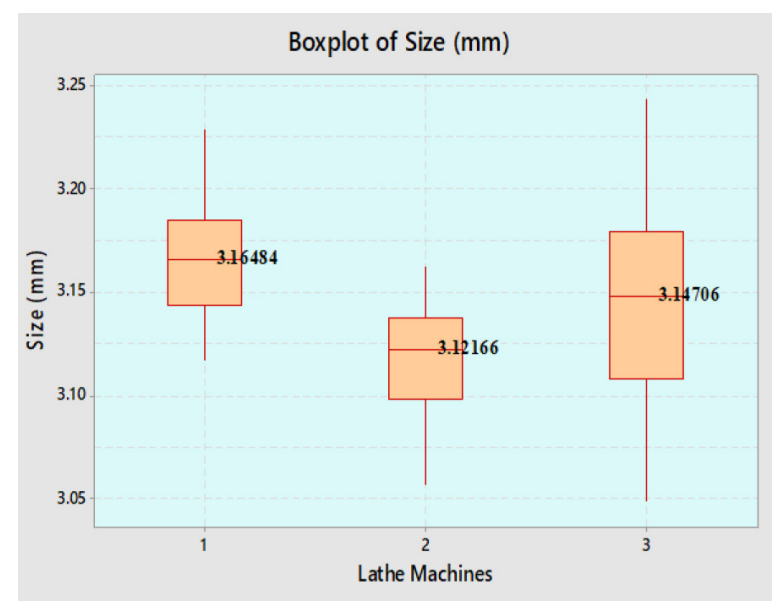

Fig. 7. Box plots comparison of sizes by machines 
Table 2. Experimental data of the process variables

\begin{tabular}{|c|c|c|c|c|c|}
\hline Observation & Lathe machine & Run & Trial time & Specimen & Size $(\mathrm{mm})$ \\
\hline 1 & 1 & 1 & 9.00 & 1 & 3.1623 \\
\hline 2 & 1 & 1 & 9.00 & 2 & 3.2054 \\
\hline 3 & 1 & 1 & 9.00 & 3 & 3.1750 \\
\hline 4 & 1 & 1 & 9.00 & 4 & 3.1775 \\
\hline 5 & 1 & 1 & 9.00 & 5 & 3.2029 \\
\hline 6 & 1 & 1 & 9.00 & 6 & 3.1724 \\
\hline 7 & 1 & 1 & 9.00 & 7 & 3.1800 \\
\hline 8 & 1 & 1 & 9.00 & 8 & 3.1419 \\
\hline 9 & 1 & 1 & 9.00 & 9 & 3.1318 \\
\hline 10 & 1 & 1 & 9.00 & 10 & 3.1877 \\
\hline$\ldots$ & 3 & $\ldots$ & $\ldots$ & $\ldots$ & $\ldots$ \\
\hline 180 & 3 & 17.00 & 10 & 3.1699 \\
\hline
\end{tabular}

that neither the data location nor the data spread seem to differ significantly by trail time of day. However, observing the findings revealed from Figure 9, which shows the box plot of the speci-

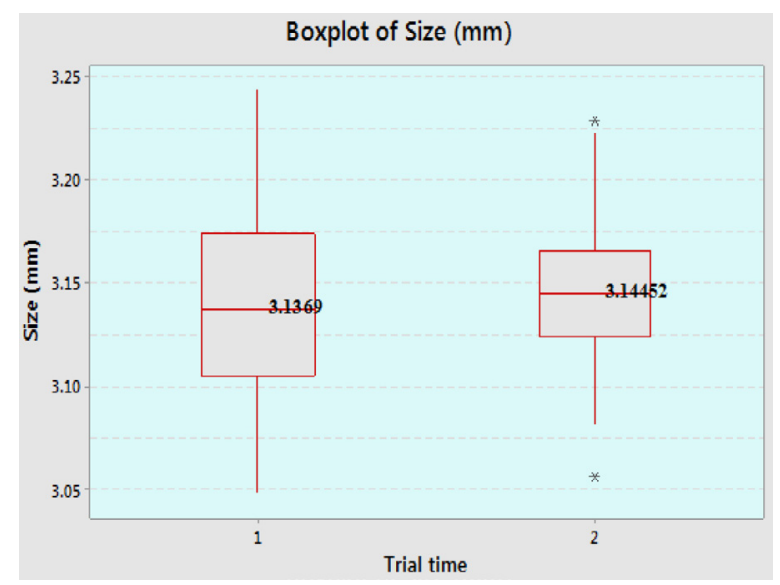

Fig. 8. Box plots comparison of trial time men with respect to size, it may be concluded that even though there are some slight differences in data location and extent between the specimen, these alterations do not demonstrate a perceptible outline and do not look significant.

Therefore, the clarification of the box plots may be established by conducting analysis of variance using equation 1 to 4 for the four factors related to lathe machines, Run, Trial time and specimen while the outcomes of ANOVA are incorporated into Table 3. The output of ANOVA is interpreted to establish the required production process characterization model and the using expression 5 to fit the model.

$$
y_{i j}=\mu+\alpha_{i}+\beta_{i}+\gamma_{i}+\varphi_{i}+e_{i j}
$$

The analysis will lead to develop the regression equation for the estimations of the effect as contrasting to the model, therefore equation 6 is introduced to establish the process of fitting a conscious function to the data set points.

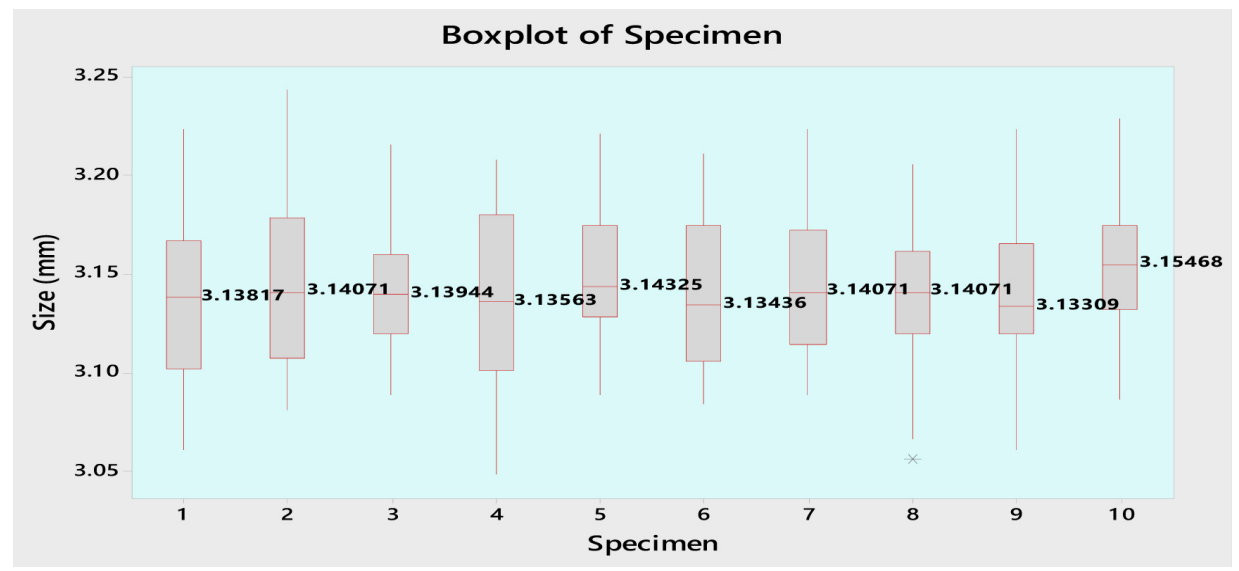

Fig. 9. Box plots comparison of specimen 
Table 3. Summary of ANOVA for four factors

\begin{tabular}{|c|c|c|c|c|c|}
\hline Source & DF & Adj SS & Adj MS & F-Value & P-Value \\
\hline LatheMachine & 2 & 0.072416 & 0.036208 & 29.90 & 0.000 \\
\hline Run & 2 & 0.002794 & 0.001397 & 1.15 & 0.318 \\
\hline Trial time & 1 & 0.001196 & 0.001196 & 0.99 & 0.322 \\
\hline Specimen & 9 & 0.005691 & 0.000632 & 0.52 & 0.857 \\
\hline Error & 165 & 0.199819 & 0.001211 & & 0.865 \\
\hline Lack-of-Fit & 164 & 0.197106 & 0.001202 & 0.44 & \\
\hline Pure Error & 1 & 0.002713 & 0.002713 & & \\
\hline Total & 179 & 0.282236 & & & \\
\hline
\end{tabular}

Table 4. Summary of ANOVA for machine factor

\begin{tabular}{|c|c|c|c|c|c|}
\hline Source & DF & Adj SS & Adj MS & F-Value & P-Value \\
\hline Lathe Machine & 2 & 0.07267 & 0.036337 & 30.69 & 0.000 \\
\hline Error & 177 & 0.20956 & 0.001184 & & \\
\hline Total & 179 & 0.28224 & & & \\
\hline
\end{tabular}

$$
y_{i j}=a_{i}+b_{i}+c_{i}+d_{i}+e_{i j}
$$

The following regression equation is obtained on the basis of expression 5 and 6 that models the process variables and to predict values within the range of the data set which clearly specifies that only the factor pertains to machine is observed to be statistically significant.

$$
\begin{aligned}
\text { Size }(\mathrm{mm})= & 3.14332+0.02376 \text { Lathe Machine_1 }-0.02530 \text { Lathe Machine_2 } \\
& +0.00154 \text { Lathe Machine_3 }+0.00357 \text { Run_1 }+0.00192 \text { Run_2 } \\
& -0.00549 \text { Run_3 }-0.00258 \text { Trial time_1 }+0.00258 \text { Trial time_2 } \\
& -0.00614 \text { Specimen_1 }+0.00261 \text { Specimen_2 }-0.00092 \text { Specimen_3 } \\
& -0.00346 \text { Specimen_4 }+0.00797 \text { Specimen_5 }-0.00388 \text { Specimen_6 } \\
& +0.00275 \text { Specimen_7 }-0.00515 \text { Specimen_8 }-0.00487 \text { Specimen_9 } \\
& +0.01107 \text { Specimen_10 }
\end{aligned}
$$

Preceding analysis of variance specified that a single machine factor was statistically significant, however the Table 4 shows the ANOVA outcomes used for lathe machine factor only. Particularly in this phase, it is the point of interest to analyze levels of means for the lathe machines variable which is summarized in Table 5 respectively.

Table 5. ANOVA for means of machines

\begin{tabular}{|c|c|c|c|c|}
\hline Machine & $\mathrm{N}$ & Mean & St Dev & $95 \% \mathrm{Cl}$ \\
\hline 1 & 60 & 3.16717 & 0.02903 & $\begin{array}{c}(3.15840, \\
3.17593)\end{array}$ \\
\hline 2 & 60 & 3.11802 & 0.02330 & $\begin{array}{c}(3.10925, \\
3.12679)\end{array}$ \\
\hline 3 & 60 & 3.14486 & 0.04654 & $\begin{array}{c}(3.13609, \\
3.15363)\end{array}$ \\
\hline
\end{tabular}

Table 6. Summary of throughput for lathe machines

\begin{tabular}{|c|c|c|c|}
\hline Machine & Run 1 & Run 2 & Run 3 \\
\hline 1 & 581 & 609 & 588 \\
\hline 2 & 662 & 609 & 591 \\
\hline 3 & 515 & 551 & 576 \\
\hline
\end{tabular}

In order to validate the production process characterization model, it is necessary to compare the data set points by generating a 4 plot of the residuals that basically apart from the fitted regression line. These data points residuals display homogeneity, normality and independence, which indicate their fitness. As per Figure 10 interpretation, the 4 plot illustration does not signpost any significant glitches with the ANOVA model. The throughput of machines is summarized Table 6.

The table values show that the machine 3 had yielded a meaningful inferior throughput which is shown graphically in Figure 11. In order to authorize the statistical significance regarding inferior 
Table 7. Summary of ANOVA for machine 3 throughput

\begin{tabular}{|c|c|c|c|c|c|}
\hline Source & DF & Adj SS & Adj MS & F-Value & P-Value \\
\hline Factor & 2 & 36.2 & 18.11 & 0.01 & 0.992 \\
\hline Error & 6 & 13210.7 & 2201.78 & & \\
\hline Total & 8 & 13246.9 & & & \\
\hline
\end{tabular}

Table 8. Summary of ANOVA for means of machine 3

\begin{tabular}{|c|c|c|c|c|}
\hline Factor & $\mathrm{N}$ & Mean & St Dev & $95 \% \mathrm{Cl}$ \\
\hline Run 1 & 3 & 586.0 & 73.6 & $(519.7,652.3)$ \\
\hline Run 2 & 3 & 589.7 & 33.5 & $(523.4,656.0)$ \\
\hline Run 3 & 3 & 585.00 & 7.94 & $(518.71,651.29)$ \\
\hline
\end{tabular}

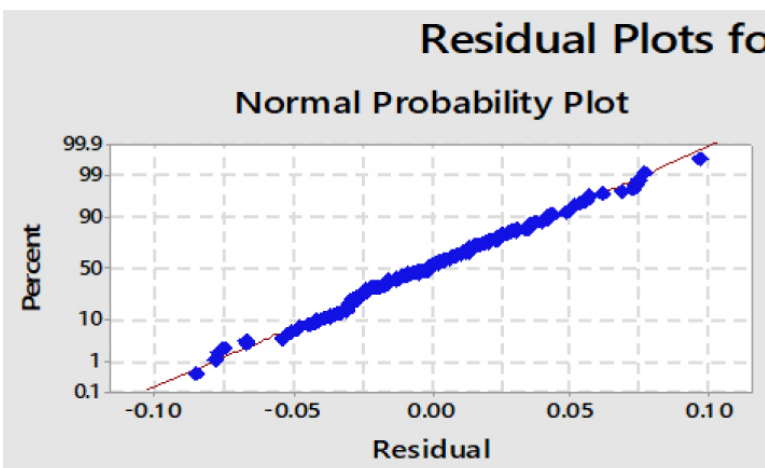

Versus Fits

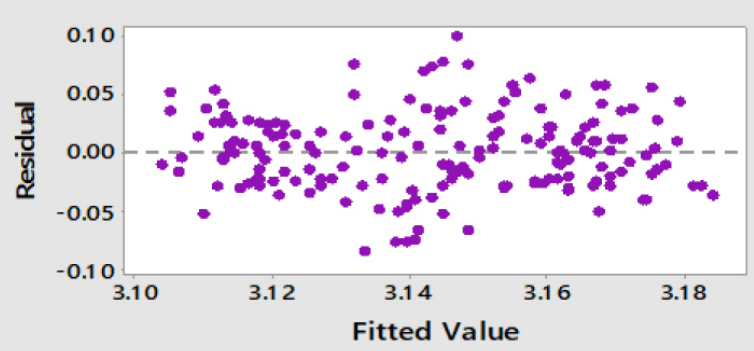

Versus Order

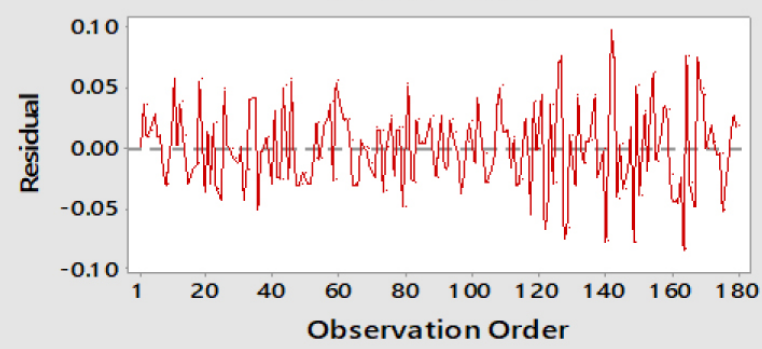

Fig. 10. Model validation comparison

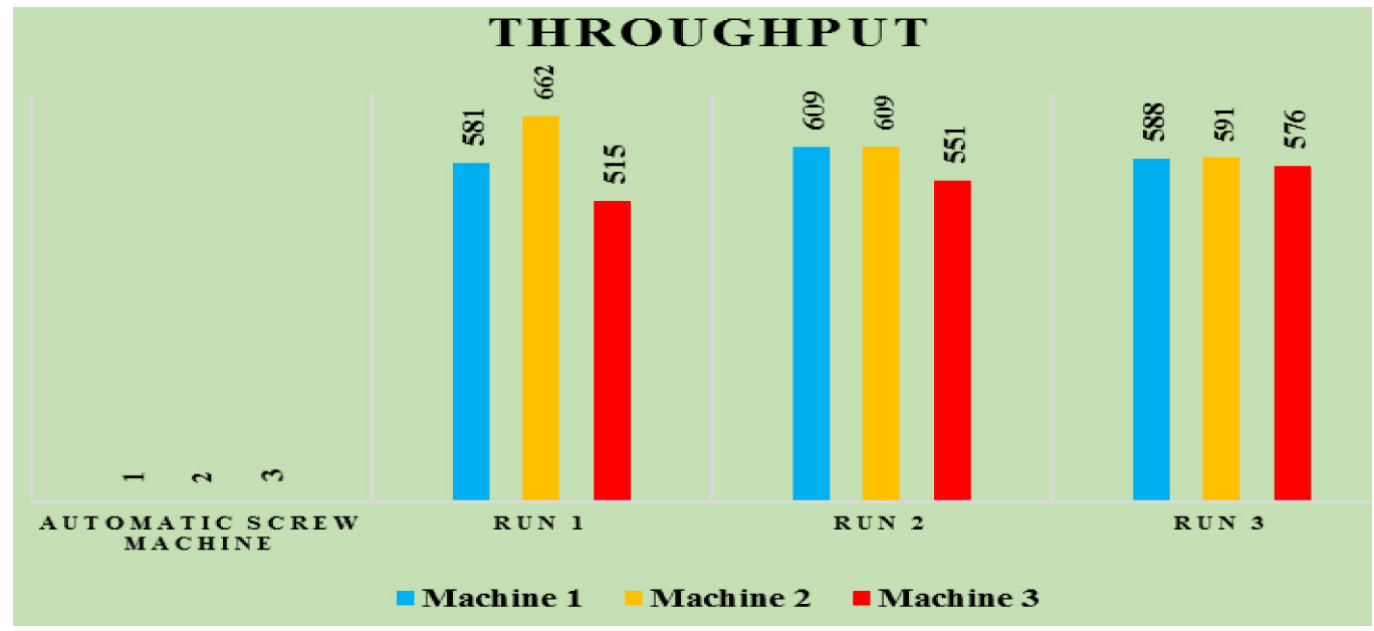

Fig. 11. Graphical comparison lathe machines throughput

throughput of automatic machine 3 , it is much desirable to run ANOVA. The result of this statistical step is presented in Table 7. Finally, the statistical summary of the level means of different runs for machine 3 is tabulated in Table 8 .

\section{CONCLUSIONS}

Productivity model parameters characteristic are based on engineering statistical data analyses to establish an appropriate model for 
improving the productivity rate. The process inputs and outputs in the form of factors and responses are branded rendering to variable type that validate the outlay of evidence they cover. It is possible for the process variables to be related with each other deprived of one of them initiating the experimental conduct on the other using the experimental design technique. The current study is based on the relevance of engineering statistical approach to analyze three different industrial lathe machines installed in frontier ceramic industry with the intention to replace one of them.

For data value comparison, Minitab 18 was utilized. For sample collection, a suitable time of the day at the start of the morning shift at 9.00 and at the end of the shift at 17.00 was considered to take 10 pieces, two times a day, for three consecutive days from each individual machine while the daily based throughput of all three machines will be exercised accordingly. The relevant machine data have been collected from the maintenance engineering department of the industrial unit. The analysis showed that both machines 1 and 2 have somewhat an equivalent inconsistency, but significantly different spreads and locations. Similarly, the throughput for machine 2 was higher with greater variability as compare to machine 1 while machine 3 had encountered significantly more variations with a low rate of throughput. On the other hand, a discussion with concerned machine operator exposed that he recognized machine 2 was not set properly. Conversely, he did not need to change machine settings since he knew that a research study was in progress hence was scared he might influence the outcomes by making of adjusting the settings. The operator also pointed out that machine had to be taken down quite a few times for slight maintenance and repairs. On the basis on the basis of the forgoing study analysis fallouts, the research team has officially suggested to substitute lathe machine 3 .

\section{Acknowledgement}

This research is fully supported by HEC grant of Research for publishing scientific articles. The author fully acknowledge support from Sarhad university of Science and Information Technology for the approved fund which makes this important research viable and effective.

\section{REFERENCES}

1. Bohannan B.J.M. and R.E. Lenski, The relative importance of competition and predation varies with productivity in a model community. The American Naturalist, 156(4), 2000.

2. Halpern L., M. Koren, and A. Szeidl, Imported inputs and productivity. Am. Econ. Rev., 2015.

3. Stock C.A. et al., Reconciling fisheries catch and ocean productivity. Proc. Natl. Acad. Sci., 2017.

4. Grace J.B. et al., Productivity and plant species richness. Nature, 2016.

5. Sparke M., B. Mullings, M.W. Wright, K. Derickson, B.R. Wilson, and M. Werner, Global Displacements: the making of uneven development in the caribbean. AAG Rev. Books, 5(1), 2017, 74-85.

6. O’Donnell T.J., Productivity and reuse in language. MIT Press, 2015.

7. La Rosa M., W.M.P. Van Der Aalst, M. Dumas, and F.P. Milani, Business process variability modeling. ACM Comput. Surv., 2017.

8. Gröner G., M. Bošković, F.S. Parreiras, and D. Gašević, Modeling and validation of business process families. Inf. Syst., 2013.

9. Moses et al., Revisiting a model of ontogenetic growth: estimating model parameters from theory and data. The American Naturalist, 171(5), 2008.

10. Acernese F. et al., Advanced Virgo: A second-generation interferometric gravitational wave detector, Class. Quantum Gravity, 32(2), 2015, p. 024001. .

11. Rozlin N., N. Masdek, A.A. Rozali, M.C. Murad, and Z. Salleh, Effect of Protein Concentration on Corrosion of Ti-6Al-4V and 316L SS Alloys. ISIJ Int., 58(8), 2018, 1519-1523.

12. Minne E. and J.C. Crittenden, Impact of maintenance on life cycle impact and cost assessment for residential flooring options. Int. J. Life Cycle Assess., vol. 20, no. 1, pp. 36-45, Jan. 2015.

13. Beall G. , M. Gallagher, K. House, ... S. I.-U. P. A. 12, and U. 2011, "Method and binder for porous articles", Google Patents.

14. Sanchez E., F. Gines, J.V Agramunt, and M. Monzo, Clay quality control in tile body production. qualicer.org, pp. 97-112.

15. Gong Y.Z. and H. Liao, Analysis and Research of Rogowski Coil Current Sensing Technology.Appl. Mech. Mater., 2014.

16. Hilfiker J.N., J. Sun, and N. Hong, Data analysis. in Springer Series in Optical Sciences, 2018.

17. Srivastava P. and N. Hopwood, A Practical Iterative Framework for Qualitative Data Analysis.Int. J. Qual. Methods, 2017.

18. Fereday J. and E. Muir-Cochrane, demonstrating rigor using thematic analysis: a hybrid approach of 
inductive and deductive coding and theme development. Int. J. Qual. Methods, 2017.

19. Bumblauskas D., H. Nold, P. Bumblauskas, and A. Igou, Big data analytics: transforming data to action. Bus. Process Manag. J., 2017.

20. Kumar R. and R. Kumar, Chapter 10. Data analysis and interpretation. Nursing Research \& Statistics, 2016.

21. Lenting K., R. Verhaak, M. ter Laan, P. Wesseling, and W. Leenders, Glioma: experimental models and reality. Acta Neuropathologica, 2017.

22. Lassmann H. and M. Bradl, Multiple sclerosis: experimental models and reality. Acta Neuropathologica, 2017.

23. Dunn B., Materials and processes for spacecraft and high reliability applications, vol. 8, 2016.

24. Urbinati A., D. Chiaroni, and V. Chiesa, Towards a new taxonomy of circular economy business models. J. Clean. Prod., 2017.
25. Yang M., P. Smart, M. Kumar, M. Jolly, and S. Evans, Product-service systems business models for circular supply chains. Prod. Plan. Control, 2018.

26. Zhou L., J. Li, F. Li, Q. Meng, J. Li, and X. Xu, Energy consumption model and energy efficiency of machine tools: A comprehensive literature review. Journal of Cleaner Production, 2016.

27. Smalheiser N.R., ANOVA, in Data Literacy, 2017.

28. Randhawa J.S. and I. S. Ahuja, Empirical investigation of contributions of $5 \mathrm{~S}$ practice for realizing improved competitive dimensions, Int. J. Qual. Reliab. Manag., 35(3), 2018, 779-810.

29. Chung M.K. Statistical and Computational Methods in Brain Image Analysis. CRC Press, 2013.

30. Laerd Statistics, One-way ANOVA in SPSS Statistics. Laerd Statistics, 2017.

31. Kim T.K., Understanding one-way anova using conceptual figures. Korean J. Anesthesiol., 2017. 